\title{
RETRACTION: Salt and water imbalance following pituitary surgery
}

Paul Grant ${ }^{1}$, Ben Whitelaw' ${ }^{1}$ Sinan Barazi ${ }^{2}$ and Simon Aylwin ${ }^{3}$

${ }^{1}$ Endocrinology and ${ }^{2}$ Department of Neurosurgery, Kings College Hospital, London, UK and

${ }^{3}$ Chemical Pathology, King's College Hospital NHS Foundation Trust, London, UK

Correspondence should be addressed to P Grant

Email

drpaul.grant@doctors.org.uk

This article has been retracted by the journal. The retraction was made before the article reached its final form in the publication process. However, the authors' accepted manuscript, prior to copy editing, page layout and proofing, was made available online as a European Journal of Endocrinology Accepted Preprint on 17 February 2012.

The article has been retracted because it was submitted without prior knowledge or consent of one or more listed authors.

The journal's ethical guidelines state that authors must 'ensure all contributors have approved the final version of the manuscript and its submission to the journal'.

Submitting author Dr Paul Grant has apologised for his actions. The journal has decided that, in view of the breach of the journal's ethical guidelines, the article should be retracted.

We apologise to our readers.

(c) 2014 European Society of Endocrinology Printed in Great Britain
Published by Bioscientifica Ltd. 